\title{
Arise, Awake and Act, till the Sustainable Development Goals are met!
}

\author{
S SACHIDANANDA KAMATH \\ National President, Indian Academy of Pediatrics, 2015 \\ drsskamath@gmail.com
}

$\mathrm{M}$ illennium Development Goals (MDGs), time period of which will end by 2015, will be replaced by the Sustainable proposed set of targ of countries on the development agenda till 2030. SDGs represent not only the agreement on the unfinished agendas of MDGs, but also the challenges ahead to build universal and transformative goals which leaves "no one behind" and "ensures the health and wellbeing of all, particularly women, children and adolescents"[1].

Over the last one and a half decade, India has achieved many gains during the journey to achieve MDGs. However, we are far behind the targets for achieving universal primary school enrolment and completion (Goal 2 ), reducing child and infant mortality (Goal 4) and improving access to adequate sanitation to eliminate open defecation (Goal 7) - all these are important as far as child health is concerned [2]. India has attained victory on maternal health to a large extent, and on many communicable diseases but it seems that we were off-track on child health. Many challenges remain in areas such as immunization coverage, malnutrition and adolescent health, especially for girls. Children are still at risk of violence, trafficking, child labour and early marriage [3].

SDGs directly related to child health are Goal 3 "Ensure healthy lives and promote well-being for all at all ages with a target as to end preventable deaths of newborns and under-five children by 2030." Other goals also address determinants of child health like ensuring inclusive and equitable quality education and promote lifelong learning opportunities for all; achieving gender equality and empower all women and girls; ensuring availability and sustainable management of water and sanitation for all; ending poverty in all its forms everywhere; ending hunger, achieve food security, and improved nutrition and promote sustainable agriculture [1]. With these targets, SDGs offer a platform for development of our country by placing children at the heart of the country's vision $[1,3]$. Universalizing health, nutrition and education has to be the key strategy for achieving sustainable development. The strategies should ensure that everyone has access to quality services, irrespective of their social background and financial status.

Government of India's vision also converge with the proposed SDGs. Government of India has already adopted the principle of "Sabka Sath, Sabka Vikas." Universal Health Assurance Scheme that the Government is planning to implement is hopeful in reducing financial hardships. More than ever before, the Government is calling for improved sanitation and dignity of women and girl children. Government's Swachh Bharat Abhiyan campaign intends to achieve a 'Clean India' by 2019. India has recently pledged to speed up the efforts to end preventable child and maternal deaths.

More vigorous and sustained efforts on improving child health will be needed, especially to meet the new global targets of zero preventable child deaths by 2030 . More investments and partnerships are the need of the hour. Efforts will also be needed to optimize human resources in health sector, to reach out to remote population, to improve monitoring of national programs, and to improve quality of health services. Public-private partnerships have to be strengthened, and information technology to be exploited to its maximum for the betterment of health services.

We have a dual responsibility to shoulder - as pediatricians and as citizens of the nation. Let us dedicate ourselves and work together to achieve the goal of zero preventable child deaths in our country.

\section{REFERENCES}

1. United Nations. Sustainable Development Goals. 2015. New York. Available from: http://www.un.org/sustain abledevelopment/sustainable-development-goals/ Accessed October 17, 2015.

2. Government of India. Millenium Development Goals: India Country Report 2015. Ministry of Statistics and Programme Implementation. New Delhi

3. UN India. India and the MDGs. Towards a Sustainable Future for All. United Nations Country Team - India. 2015. 